Bond University

Research Repository

\title{
Social anxiety and alexithymia in relation to problematic drinking and theory of mind
}

\author{
Lyvers, Michael; Scott, Kaitlin; Thorberg, Fred Arne
}

Published in:

American Journal of Psychology

DOI:

10.5406/amerjpsyc.132.3.0325

Licence:

Other

Link to output in Bond University research repository.

Recommended citation(APA):

Lyvers, M., Scott, K., \& Thorberg, F. A. (2019). Social anxiety and alexithymia in relation to problematic drinking and theory of mind. American Journal of Psychology, 132(3), 325-342.

https://doi.org/10.5406/amerjpsyc.132.3.0325

\footnotetext{
General rights

Copyright and moral rights for the publications made accessible in the public portal are retained by the authors and/or other copyright owners and it is a condition of accessing publications that users recognise and abide by the legal requirements associated with these rights.

For more information, or if you believe that this document breaches copyright, please contact the Bond University research repository coordinator.
} 
Social Anxiety and Alexithymia in Relation to Problematic Drinking and Theory of Mind Michael Lyvers, Ph.D.

Kaitlin Scott, BSc(Honours)

School of Psychology

Bond University

Gold Coast Qld Australia

Fred Arne Thorberg, Ph.D.

National Centre for Dual Diagnosis

Innlandet Hospital Trust

Brumunddal Norway 


\begin{abstract}
Cognitive models of social anxiety posit inaccurate appraisal of emotional states as a core feature. Such inaccurate appraisal also characterizes alexithymia, a trait defined by difficulties in identifying and describing emotional feelings and an externally oriented thinking style. As both social anxiety and alexithymia have been linked to alcohol misuse and deficient theory of mind, the degree to which alexithymia might account for these associations with social anxiety merits investigation. The current study explored relationships between social anxiety (specifically social interaction anxiety), alexithymia, problematic drinking, and theory of mind after controlling for comorbid depression in a non-clinical sample of 242 participants (93 males) ranging in age from 18 to 35 years $(M=$ 23.22 years, $S D=4.48$ ). They completed an online questionnaire battery that included well-known measures of social anxiety (Social Interaction Anxiety Scale), alexithymia (Toronto Alexithymia Scale 20), theory of mind (Reading the Mind in the Eyes Test Revised), depression (Depression Anxiety Stress Scales - Depression Scale), and problematic drinking (Alcohol Use Disorders Identification Test). In hierarchical regression models, social anxiety predicted alexithymia even after controlling for depression and demographic factors; alexithymia mediated relationships between social anxiety and both problematic drinking and deficient theory of mind. Assessment of alexithymia in those with social anxiety may potentially offer insight and directions for treatment.
\end{abstract}

Keywords: Social Anxiety, Alexithymia, Alcohol Abuse, Theory of Mind 
As a group, anxiety disorders comprise the most common mental health problems (Baxter, Patton, Scott, Degenhardt, \& Whiteford, 2013). Of the anxiety disorders, Social Anxiety Disorder (SAD) affects the greatest proportion of the general population and is recognized as the fourth most common psychiatric disorder worldwide (Ruscio et al., 2008). It is a chronic and pervasive disorder with an estimated lifetime prevalence of $12 \%$ (Kessler et al., 2005). SAD is characterized by intense fear and avoidance of social and performance situations that leads to clinically significant interference with an individual's life, often impacting on career and interpersonal relationships (American Psychiatric Association, 2013; Schlenker \& Leary, 1982). Subclinical social anxiety is even more common and can also be highly problematic for sufferers. A large-scale German study (Fehm, Beesdo, Jacobi \& Fiedler, 2008) found that subclinical social anxiety was associated with a similar pattern of disruption across diverse aspects of life to SAD, including satisfaction with familial and other social relationships, job and financial status, and satisfaction with life overall. Subclinical social anxiety is also a known risk factor for alcohol misuse in young adults (Kairouz, Kliksman, Demers \& Adlaf, 2002; Schry \& White, 2013; Thomas, Randall \& Carrigan, 2003), presumably because alcohol acts as a "social lubricant" due to its anxiolytic and disinhibiting effects (Abrams, Kushner, Medina \& Voight, 2001, 2002; Thomas et al., 2007).

A recent large-scale Norwegian twin study (Torvik et al., 2016) indicated that although genetic factors substantially influence vulnerability to SAD, experiential factors play a critical role in its manifestation. The condition thus typically develops in adolescence during a time when social and peer relationships are extremely important (Iverach \& Rapee, 2014). Individuals with social anxiety can experience considerable subjective and somatic distress during social interactions, often marked by increased heart rate, sweating and trembling (Stemberger et al., 1995). Given the adverse impacts of both 
clinical and subclinical social anxiety on an individual's functioning and overall quality of life, and on alcohol-related risk in young adults as described earlier, elucidation of factors likely to promote and maintain social anxiety is warranted. This is especially the case for young adults, as their pursuits of fulfilling social relationships and careers are often adversely affected by the condition (Fehm et al., 2008).

\section{Social Anxiety and Alexithymia}

Alexithymia, a term first coined by Sifneos (1973), is a subclinical personality trait (Thorberg et al., 2016a) that involves a cognitive-affective disturbance with markedly reduced symbolic thinking, limited ability in identifying and verbalizing emotions and an impoverished fantasy life. Salient features of alexithymia include poor ability to identify and describe feelings, an externally oriented thinking style and difficulties differentiating feelings and somatic sensations of emotional arousal (Nemiah, Freyberger \& Sifneos, 1976). Highly alexithymic individuals are often preoccupied with external events and tend not to solicit help or comfort from others due to their interpersonal difficulties, which are often reflected in self-reports of loneliness (Qualter, Quinton, Wagner \& Brown, 2009). The etiology of alexithymia is unknown; a large-scale twin study indicated low to moderate heritability (Jorgensen, Zachariae, Skytthe \& Kyvik, 2007), suggesting that developmental influences such as parental neglect and inadequate parental bonding in childhood may be crucial (Aust, Alkan Härtwig, Heuser \& Bajbouj, 2013; Evren et al., 2009; Thorberg et al., 2011b).

Alexithymia has been linked to a variety of psychological disorders including depression (Li, Zhang, Guo, \& Zhang, 2015), anxiety (De Gucht, Fischler, \& Heiser, 2004; de Timary, Luts, Hers \& Luminet, Filee, 2008), obsessive-compulsive disorder (Roh, Kim, \& Kim, 2011), schizophrenia (O’Driscoll, Laing, \& Mason, 2014), autism spectrum disorder (Berthoz \& Hill, 2005), post-traumatic stress disorder (Frewen, Dozois, Neufeld, 
\& Lanius, 2008), and eating disorders (Pinaquy, Chabrol, Simon, Louvet \& Barbe, 2003). Approximately 28\% (Cox, Swinson, Shulman, \& Bourdeau, 1995) to 58\% (Fukunishi et al., 1997) of patients diagnosed with SAD have been reported to be highly alexithymic. Emotion suppression has been reported to characterize both social anxiety (Spokas, Luterek, \& Heimberg, 2009) and alexithymia (e.g., Swart, Kortekaas \& Aleman, 2009). Difficulties identifying and communicating one's feelings can present major impediments to social interaction (Edel et al., 2010), hence trait alexithymia might promote social anxiety starting in adolescence or earlier; however, there are other plausible explanations of the relationship as well. A highly alexithymic child or adolescent is likely to have deficient social skills and suffer interpersonal difficulties due to their poor ability to interpret and appropriately respond to the emotions of others (Lyvers, McCann, Coundouris, Edwards \& Thorberg, 2018; Vanheule, Desmet, Meganck \& Bogaerts, 2006), which would presumably promote anxiety in social interactions. Alternatively, given that the onset of social anxiety most often occurs in early adolescence, learned avoidance of social situations that would normally aid in developing knowledge of complex emotional states could plausibly lead to poor emotion knowledge and alexithymia. As a result, socially anxious individuals may be less likely to learn about and fully understand their own emotions (O'Toole et al., 2013) as well as those of others.

Yet another possibility is that alexithymia may in some cases be a reaction to intense anxiety, as so-called secondary alexithymia (Evren \& Evren, 2007; Freyberger, 1977). Freyberger distinguished between primary and secondary alexithymia. Primary alexithymia is regarded as a personality trait that is presumably genetic or biological in origin, whereas secondary alexithymia is a reaction to intense or chronic negative affect or psychological stress (Grabe et al., 2000; Summerfeldt et al., 2010). Some studies have supported this primary-secondary distinction (e.g., Dalbudak et al., 2013; Fukunishi et al., 
1997; Haviland et al., 1994), whereas others have not (Mikolajczak \& Luminet, 2006). In any case, as cognitive models of social anxiety posit the perpetuating role played by inaccurate appraisals of emotional states (Clark \& Wells, 1997; Wells, 1997) - which is also characteristic of alexithymia - in the present study social anxiety was anticipated to be positively associated with alexithymia in a nonclinical sample of young adults, as was found in a recent study by Dalbudak et al. (2013) in a nonclinical sample of university students.

Dalbudak et al. (2013) also reported that social anxiety was positively associated with depression in their nonclinical sample of young adults. Other evidence suggests that the association between social anxiety and alexithymia may reflect the high comorbidity of both with depression (Ertekin, Koyuncu, Ertekin, \& Ozyildriim, 2015). Erekin et al. reported that the positive association of social anxiety with alexithymia in a clinical sample was diminished after controlling for comorbid depression. In contrast, Evren and Evren (2007) found that the association of social anxiety with alexithymia in a sample of dermatological patients was independent of depression. Given inconsistent findings, the present study assessed whether depression could account for the relationship between social anxiety and alexithymia, or if the relationship persists even after controlling for depression.

\section{Social Anxiety, Alexithymia, and Theory of Mind}

Cognitive processing biases have been theorized to contribute to the maintenance of social anxiety, including attentional (Amin, Foa, \& Coles, 1998), memory (Foa, GilboaSchechtman, Amir, \& Freshman, 2000), and interpretative biases (Amin et al., 1998) for socially relevant information. Socially anxious individuals may lack an accurate view of how others perceive them due to deficits in comprehending the mental and emotional states of others in social situations (Hezel \& McNally, 2014; Washburn et al., 2016), 
which is also characteristic of alexithymia (Lyvers, Kohlsdorf, Edwards \& Thorberg, 2017; Lyvers, McCann, Coundouris, Edwards \& Thorberg, 2018). The ability to understand, identify and reason about the subjective states of others is known as theory of mind (Frith \& Frith, 2003; Moriguchi et al., 2006; Premack \& Woodruff, 1978; Onuoha, Quintana, Lyvers, \& Guastella, 2016). Theory of mind reasoning involves two component processes: detecting or deciphering others' states based on the immediate observable evidence, and reasoning about those states to predict or understand others' behavior (Sabbagh, 2004). If an individual has difficulty decoding and reasoning about others' emotions, thoughts, and intentions, they are likely to find social situations especially challenging (Hezel \& McNally, 2014). Further, their failure to understand and predict the behaviors of others, and to comprehend how others view them, would seem likely to promote and maintain anxiety in the context of social interaction.

Theory of mind deficits, such as difficulties evaluating others' thoughts and feelings, may thus pose a significant risk for impaired interpersonal functioning and social anxiety (Hezel \& McNally, 2014; Washburn et al., 2016). Washburn et al. examined performance on the Reading the Mind in the Eyes Test (RMET; Baron-Cohen, Wheelwright, Hill, Raste, \& Plumb, 2001), a widely used index of theory of mind, in patients with SAD, depression, comorbid SAD and depression, and a community control sample. Those with pure SAD demonstrated the poorest emotion recognition performance. Hezel and McNally administered two theory of mind tasks to 80 university students, with 40 meeting criteria for SAD. Their results indicated that participants with SAD performed significantly worse on both theory of mind tasks in comparison to controls. Those with SAD appeared to over-interpret the mental and emotional states of others, potentially leading to misunderstandings in social interactions. 
Correctly inferring the emotions of others based on external cues logically requires an ability to recognize one's own emotional feeling states (Lombardo et al., 2011). Recent research has thus documented negative relationships between alexithymia and facial recognition of emotions as assessed by tasks such as the RMET (Demers \& Koven, 2015; Grynberg et al., 2013; Lyvers et al., 2017; Lyvers, McCann et al., 2018). Highly alexithymic individuals are not only impaired in their ability to recognize their own feelings but also in their ability to recognize the feelings of others. The relationship between alexithymia and deficient theory of mind is regarded as an increasingly important issue in clinical work (Lane et al., 2015), especially given the impact of interpersonal relationships on psychological health. The ability of highly alexithymic individuals to understand and deal with subtleties of social interaction tends to be poor, and their predictions of others' responses and actions are often inaccurate (Wastell \& Taylor, 2002). Given such evidence, alexithymia would seem likely to account for at least part of the relationship between social anxiety and deficient theory of mind, another hypothesis examined in the present investigation.

\section{Social Anxiety, Alexithymia, and Problematic Drinking}

Between 24\% (Magee et al., 1996) and 48\% (Buckner et al., 2008) of individuals with a lifetime diagnosis of SAD additionally meet the criteria for a lifetime alcohol use disorder (AUD) diagnosis, compared to a lifetime prevalence rate of $15 \%$ for AUD in the general population (Kessler et al., 2005). Comorbidity of social anxiety and problematic drinking has been reported in both clinical and nonclinical samples, including university students (Gilles, Turk, \& Fresco, 2006; Kairouz, Kliksman, Demers, \& Adlaf, 2002; Thomas, Randall, \& Carrigan, 2003). Alcohol abuse and dependence often precede development of full-blown SAD, suggesting that heavy drinking may be a learned response to subclinical social anxiety in such cases (Gilles et al., 2006). Experimental 
research indicates that alcohol consumption can decrease performance anxiety in those with SAD (Abrams et al., 2001), and that they increase alcohol intake following a performance task (Abrams et al., 2002).

A continued reliance on anxiolytic substances such as alcohol to self-medicate is likely to increase the risk of problematic use and dependence. A longitudinal study by Buckner et al. (2008), who assessed 1709 adolescents over 14 years, found that social anxiety was a unique risk factor for the later development of alcohol dependence. Buckner et al. concluded that the relationship between social anxiety and alcohol dependence was relatively specific, as no such relationship was evident for other mood or anxiety disorders in their sample.

Interestingly, the use of alcohol to cope with negative emotions such as anxiety and stress has been reported to increase the risk of alcohol-related problems regardless of the quantity of alcohol use (Cooper et al., 1995). For example, Gilles et al. (2006) assessed 188 undergraduate students and found that social anxiety was a significant predictor of alcohol dependence and problems caused by alcohol, but not alcohol consumption. Given that their university student sample showed high levels of alcohol consumption overall, social anxiety may not necessarily be associated with higher alcohol consumption especially in heavy social drinking samples, such as young adults at university - but nevertheless may remain a risk factor for problematic drinking including dependence. The present study thus examined problematic drinking in relation to social anxiety in a nonclinical sample of young adults, independent of consumption levels.

High levels of alexithymia are common in those diagnosed with AUD (Thorberg et al., 2009). The disinhibiting and anxiolytic effects of alcohol may help those with alexithymia improve poor interpersonal functioning, relieve social anxiety (Lyvers et al., 2012,2018 ) and aid in overcoming their inability to express or experience emotions 
(Thorberg et al., 2016b). Considering that social anxiety, like alexithymia, is also a potential risk factor for AUD, exploring the role of alexithymia in such relationships may provide considerable insight. Individuals with high levels of alexithymia may use substances such as alcohol to compensate for their inability to modulate affect (Speranza et al., 2004). Lyvers et al. (2012) reported an association in university students between difficulties identifying feelings and drinking to cope with negative emotions, suggesting that deficiencies of emotional self-regulation can lead to self-medication with alcohol. Thorberg et al. (2011a) reported that the relationship between alexithymia and alcohol dependence in a clinical sample was mediated by the expectation that alcohol would cause affective changes. Alexithymia may thus play a mediating role in the relationship between social anxiety and problematic drinking, an idea examined in the current study.

\section{The Present Study}

As previous studies have indicated associations of social anxiety with alexithymia in both clinical and nonclinical samples (e.g., Cox et al., 1995; Dalbudak et al., 2013; Fukunishi et al., 1997) as well as problematic drinking (Kairouz et al., 2002; Schry \& White, 2013; Thomas et al., 2003) and deficient theory of mind (Hezel \& McNally, 2014; Washburn et al., 2016), the potential role of alexithymia in the links between social anxiety and problematic drinking or deficient theory of mind merits investigation, as does the related question as to whether the association between social anxiety and alexithymia is independent of depression. The present study explored these issues in a nonclinical sample with the aim of elucidating possible perpetuating factors in both social anxiety and problematic drinking. The role of alexithymia is important as this trait is a likely risk factor for both types of problems and has been reported to respond to cognitive therapy (Thorberg et al., 2016a). Based on the evidence and theory discussed earlier, the present study thus tested three hypotheses: (1) self-reported anxiety regarding social interaction 
would predict alexithymia even after controlling for depression; (2) alexithymia would mediate the expected relationship between social anxiety and problematic drinking; and (3) alexithymia would mediate the expected relationship between social anxiety and deficient theory of mind.

\section{Method}

\section{Participants}

A total of 301 individuals volunteered to participate in this study. After removal of cases outside the desired age range of 18-35 years in order to minimize cohort and other age-related factors (note that the legal drinking age in Australia is 18), those who were not at least occasional consumers of alcohol (as the study examined predictors of alcoholrelated risk among social drinkers), and multivariate outliers (identified by Mahalanobis Distance, $p<.001$ ), the final sample consisted of 242 volunteers (93 males) from two universities in southeast Queensland, Australia $(n=178)$ and from the local community $(n$ $=64)$. Participants ranged in age between 18 and 35 years $(M=23.22, S D=4.48)$. Participants reported having completed education to the level of undergraduate or trade school (44\%), grade $12(43 \%)$, postgraduate $(11 \%)$, and before grade $12(2 \%)$. Most participants identified as Australian (72\%), with the remainder including American (7\%), British (5\%), New Zealander (4\%), South African (2\%) and Other (10\%). In line with previous findings on the population prevalence of definite or high alexithymia as indicated by Toronto Alexithymia Scale cut-off score (Bagby, Taylor, \& Parker, 1994), 18\% of the sample met this criterion. The Alcohol Use Disorders Identification Test (Saunders et al., 1993 ) identified $46 \%$ of the sample as low-risk drinkers, $43 \%$ as risky or hazardous drinkers, and $12 \%$ as harmful or dependent drinkers. Although not diagnostic of SAD, the suggested Social Interaction Anxiety Scale cut-off score (Mattick \& Clarke, 1998) 
identified $13.2 \%$ of the sample as likely having SAD, very close to the $13.6 \%$ prevalence of SAD in young adults reported by Kessler et al. (2005).

\section{Materials}

Demographic Questionnaire. The 12-item self-report questionnaire assessed participants' age, gender, country of origin, student status, and highest level of education attained, as well as information on alcohol and other substance use.

Social Interaction Anxiety Scale (SIAS; Mattick \& Clarke, 1998). The SIAS is a 20-item self-report measure that assesses distress associated with ordinary social interactions. Items are self-statements describing one's characteristic reaction to situations involving social interaction such as "I have difficulty talking with other people" and "I feel I'll say something embarrassing when talking." Items are rated on a five-point Likert scale ranging from 0 Not at all characteristic of me to 4 Extremely characteristic of me.

Summation of item responses yields a total score that can range from 0 to 80 . Higher scores indicate higher levels of social anxiety, with a score of 43 or more suggestive (though not diagnostic) of SAD. The SIAS has been reported to detect differences between socially anxious patients and those with other anxiety disorders in an anxiety disorder unit (Peters, 2000). Peters also reported evidence for construct validity as the SIAS converged with other measures of social anxiety such as the Social Phobia Scale $(r=.73)$ and the Social Phobia and Anxiety Inventory $(r=.85)$. The Cronbach's alpha reliability coefficient for the SIAS in the current study was high $(\alpha=.91)$.

Toronto Alexithymia Scale 20 (TAS-20; Bagby, Parker \& Taylor, 1994). The TAS-20 is an empirically derived self-report index of alexithymia consisting of 20 items that assess the three facets of this trait: difficulty identifying feelings (DIF; 7 items, e.g., "I am often confused about what emotions I am feeling"), difficulty describing feeling (DDF; 5 items, e.g., "It is difficult for me to find the right words for my feelings"), and externally 
oriented thinking (EOT; 8 items, e.g., "I prefer to talk to people about their daily activities rather than their feelings"). Items are rated on a five-point Likert scale ranging from 1 Strongly Disagree to 5 Strongly Agree. Summation of responses generates a total score signifying the severity of alexithymia ranging between 20 and 100. Based on empirically derived cut-offs, a total score greater than 61 indicates definite or high alexithymia, a score between 51 and 60 indicates borderline alexithymia, and a score less than 51 indicates low or no alexithymia (Bagby, Taylor \& Parker, 1994). The TAS-20 has been shown to be a psychometrically sound index of alexithymia (Taylor, Bagby \& Parker, 2003; Thorberg et al., 2010). The TAS-20 showed an acceptable Cronbach's alpha reliability coefficient in the current study $(\alpha=.79)$.

\section{Depression Anxiety Stress Scales-21 (DASS-21) Depression Scale (Lovibond \&}

Lovibond, 1995). The DASS-21 is a self-report measure used to assess negative emotional states experienced over the past week. It contains 21 items assessing three factors, Depression, Anxiety, and Stress, with 7 items for each. The Depression Scale was used in the current study. Items such as "I felt that life was meaningless" are rated on a four-point Likert scale ranging from 0 Did not apply to me at all to 3 Applied to me very much, or most of the time. Higher scores on this scale indicate higher levels of depression. Concurrent validity of the Depression Scale was demonstrated by high positive correlations with the Beck Depression Inventory (Antony et al., 1998). Cronbach's alpha reliability coefficient of the Depression Scale in the current study was very high $(\alpha=.92)$.

\section{Reading the Mind in the Eyes Test - Revised (RMET-R; Baron-Cohen et al.,}

2001). The RMET-R is a theory of mind measure that assesses emotion recognition via pictures of men's and women's eyes. It consists of 36 grey-scale photographs of human eyes (18 males) expressing a complex mental state. The photographs are presented individually with four mental state adjectives (one target word and three foils) displayed 
around the photo, e.g., "cautious," "insisting," "bored," "aghast." Where possible, the foils have similar valence to the target word. Participants were asked to indicate the adjective that best describes what the person in the photograph was feeling. One point is assigned per correct response and summation of correct responses provides a total score. Scores can range from 0 to 36, with higher scores indicating more accurate theory of mind. Test retest reliability has been found to be moderate to high over a 30-day period ( $r=.83$; Vallante et al., 2012). The RMET-R has been shown to differentiate among groups that theoretically differ in their theory of mind abilities, such as groups with and without Autism Spectrum Disorder or Asperger's syndrome (Olderbak et a., 2015). The Cronbach's alpha reliability coefficient for the RMET-R in the current study was high $(\alpha=.90)$.

Alcohol Use Disorders Identification Test (AUDIT; Saunders et al., 1993). The AUDIT is a self-report screening tool to indicate hazardous or harmful alcohol use. It was created over two decades in collaboration with the World Health Organization (Babor, Higgins-Biddle, Saunders \& Monteiro, 2001). Responses are selections from a three-point ( 2 items) or five-point ( 8 items) Likert scale scored from 0 to 4 , with anchors depending on the question. Items assess three factors: alcohol consumption, measured by three items (e.g., "How often do you have a drink containing alcohol?"); alcohol dependence, measured by three items (e.g., "How often during the last year have you found that you were not able to stop drinking once you had started?"); and alcohol-related problems, measured by four items (e.g., "Have you or someone else been injured because of your drinking?"). Summation of the subscale items provides a score for each subscale. Summation of all items provides a total score, with scores of 8-15 indicating hazardous drinking and scores of 16 and above indicating harmful drinking (Saunders et al., 1993). The AUDIT has demonstrated concurrent validity with the Michigan Alcoholism Screening Test (Bohn, Babor, \& Kranzler, 1995; Conley, 2001). Given previous evidence 
that SAD may be associated with problematic drinking independently of consumption levels in heavy drinking samples of young adults (Gilles et al., 2006), the current study used a composite index combining the alcohol dependence and alcohol-related problems subscales. This index showed good reliability in the present sample $(\alpha=.81)$.

\section{Procedure}

The ethics committees of both universities granted approval of the study protocol prior to data collection. Questionnaires were administered via Qualtrics, a research software website. The hyperlink to the study was emailed to students at the two universities and also shared via a dedicated Facebook page. The link directed prospective participants to an explanatory statement that contained general information about the study, specified that responses would be anonymous, and provided contact details of the researchers. Prospective participants were also informed that their participation would require 25-30 minutes of their time. Incentives included course credit in a psychology subject for those recruited from one university, and entrance into a raffle for a $\$ 50$ gift voucher for the remainder. In order to receive the incentive, participants had to provide a screen-shot of the final page to send to the researcher's email address upon completion.

\section{Results}

The data were analyzed using SPSS Version 23. Missing values analysis showed that well less than $5 \%$ of data were missing, thus mean substitution was used for the missing data. G* Power 3.1 (Faul, Erdfelder, Lang, \& Buchner, 2009) indicated that the sample yielded adequate power for detecting a medium effect size.

\section{Correlations}

Pearson's correlations as well as means and standard deviations for all variables are displayed in Table 1. As predicted, SIAS social anxiety scores displayed significant positive correlations with TAS-20 total alexithymia scores, as well as with subscale scores 
for DDF and DIF, but not EOT, consistent with previous reports (Dalbudak et al., 2013). Also as predicted, SIAS scores were significantly positively correlated with both the AUDIT alcohol dependence and alcohol-related problems subscales, which were combined to form a single index of problematic drinking. In line with previous findings (Gilles et al., 2006), SIAS did not correlate with the alcohol consumption subscale in this young adult sample. Further, as predicted both SIAS and TAS-20 scores displayed significant negative correlations with the theory of mind index (RMET-R scores). TAS-20 was significantly positively correlated with the AUDIT and its subscales as in previous work cited earlier. A highly significant association was found between likely SAD and definite or high alexithymia based on suggested cut-off scores of the SIAS and TAS-20 respectively, such that $41 \%$ of participants with likely SAD were highly alexithymic, compared to only $15 \%$ of those without likely SAD, $\chi^{2}(1)=12.49, p<.0001$.

\section{$<$ INSERT TABLE 1 NEAR HERE $>$}

\section{Social Anxiety Predicts Alexithymia After Controlling for Depression}

To test the hypothesis that social anxiety would be positively associated with alexithymia even after controlling for depression, a hierarchical regression was conducted with alexithymia (TAS-20 scores) as the criterion variable. Age, gender and DASS-21 Depression scores were entered at step 1 as covariates, and SIAS scores were entered at step 2. Step 1 accounted for $28 \%$ of the variance in alexithymia, $F(3,238)=30.04, p<$ .0001 , with depression the only significant predictor (see Table 2). Addition of the SIAS index of social anxiety at step 2 explained an additional 14\% of variance in alexithymia, $\Delta F(1,237)=57.62, p<.0001$, and the model remained significant, accounting for $42 \%$ of the variance in alexithymia, $F(4,237)=42.29, p<.0001$. Social anxiety was the strongest predictor of alexithymia in the final model, followed by depression (see Table 2). 
To test the hypotheses that, after controlling for the covariates of age, gender and depression, alexithymia would mediate the associations of social anxiety with (1) problematic drinking and (2) theory of mind, mediation was tested via regression following the conservative Baron and Kenny (1986) steps approach. According to Baron and Kenny, a mediated relationship is indicated when certain criteria are met. Firstly, the independent variable predicts the dependent variable. Secondly, the independent variable predicts the mediator variable. Thirdly, the mediator variable predicts the dependent variable. Finally, the relationship between the independent variable and the dependent variable is significantly reduced after including the mediator (partial mediation) or becomes non-significant in the presence of the mediator (full mediation).

\section{Social Anxiety and Problematic Drinking: Full Mediation by Alexithymia}

In a hierarchical regression, after controlling for age, gender and depression at step 1, social anxiety at step 2 predicted problematic drinking (AUDIT dependence + alcoholrelated problems), $\Delta F(1,237)=4.49, p=.03$, accounting for $2 \%$ of the variance. As expected, social anxiety was a significant positive predictor (see Table 3). As reported earlier, social anxiety also predicted alexithymia even after controlling for depression (see Table 2). Thus, in a three-step hierarchical regression predicting problematic drinking, the covariates age, gender and depression were entered at step 1, social anxiety was entered at step 2, and alexithymia was entered at step 3. Social anxiety was a significant predictor at step 2 (see Table 3), however it became nonsignificant at step 3 after adding alexithymia to the model. Alexithymia accounted for an additional $5 \%$ of variance in problematic drinking, $\Delta F(1,236)=13.75, p<.0001$. The final model was significant, $F(5,236)=6.81$, $p<.0001$, accounting for $13 \%$ of the variance in problematic drinking. Sobel test (Sobel, 1982) was significant, $z=3.33, p=.001$, indicating full mediation (see Figure 1). 


\section{Social Anxiety and Deficient Theory of Mind: Partial Mediation by Alexithymia}

In a hierarchical regression, after controlling for age, gender and depression at step 1, social anxiety at step 2 predicted performance on the theory of mind task, $\Delta F(1,237)=$ $12.44, p<.0001$, accounting for $5 \%$ of additional variance over and above the $5 \%$ of variance explained in step 1 . As expected, social anxiety was a negative predictor of theory of mind (see Table 4). Male gender was also associated with worse performance. At step 3, addition of alexithymia to the model explained an additional $2 \%$ of variance in theory of mind, $\Delta F(1,236)=5.38, p=.02$, and the final model was significant, $F(5,236)=6.03, p$ $<.0001$, accounting for $11 \%$ of the variance in theory of mind task performance. Gender was the strongest predictor, followed by alexithymia (see Table 4). Both social anxiety and alexithymia were significant in the final model, however the influence of social anxiety was substantially reduced; Sobel test (Sobel, 1982) was significant, $z=2.22, p=.03$, indicating partial mediation (see Figure 2).

$<$ INSERT TABLE 4 NEAR HERE $>$ $<$ INSERT FIGURE 2 NEAR HERE $>$

\section{Discussion}

Relationships among variables were consistent with expectations, such that social anxiety was significantly correlated with alexithymia, theory of mind, problematic drinking and depression in expected directions. Furthermore, social anxiety predicted alexithymia even after controlling for depression, indicating that the relationship between social anxiety and alexithymia does not simply reflect their comorbidity with depression as has been previously suggested (Ertekin et al., 2015; Evren \& Evren, 2007). In the present sample, $41 \%$ of individuals with SIAS scores that were suggestive (though not diagnostic) of SAD also had TAS-20 scores above the cut-off for definite or high alexithymia, compared to only $15 \%$ of those whose SIAS scores did not suggest SAD. This association is consistent with the hypotheses discussed earlier on how social anxiety could be an 
outcome of alexithymia, or vice-versa. Social anxiety scores were specifically correlated with the DIF and DDF components of alexithymia as indexed by the corresponding TAS20 subscales, but not with EOT, which was consistent with previous work (Cox et al., 1995; Dalbudak et al., 2013; Fukunishi et al., 1997).

The present study also provided support for a mediating role of alexithymia in the relationship between social anxiety and problematic drinking, the latter operationally defined by combining the alcohol dependence and alcohol related problems subscales of the AUDIT. This result was consistent with previous reports of positive relationships between social anxiety and both alcohol dependence and alcohol-related problems (Buckner et al., 2008; Morris, Stewart \& Ham, 2005), and between alexithymia and both alcohol dependence and alcohol-related problems (Lyvers et al., 2012; Speranza et al., 2004; Thorberg et al., 2009, 2010). Interestingly, social anxiety was unrelated to alcohol consumption in the present study, consistent with previous findings in young adults (Gilles et al., 2006). Use of alcohol to cope with negative emotions - a drinking motive that has been reported to characterize both social anxiety and alexithymia, as described earlier - has specifically been linked to an increased risk of alcohol dependence (Kuntsche, Knibbe, Gmel \& Engels, 2005).

A recent study (Lyvers, Hanigan \& Thorberg, 2018) found that both social anxiety (as indexed by SIAS) and alexithymia (as indexed by TAS-20) were positive predictors of coping motives for drinking, and that alexithymia fully mediated the relationship between social anxiety and coping motives. However, those who experience high levels of anxiety during social interactions may not only learn to use alcohol to alleviate their anxiety; the difficulties identifying and expressing feelings in those with high levels of alexithymia may further promote reliance on drinking as a means to induce affective changes via disinhibition and (at least subjectively) improve interpersonal functioning and emotional 
expression (Lyvers et al., 2012; Thorberg et al., 2011a, 2016b). Highly alexithymic individuals have been reported to show significantly earlier onset and longer duration of problematic drinking compared to those with low or no alexithymia (see review by Thorberg et al., 2009). Alexithymia associated with social anxiety may thus encourage a dependence on the anxiolytic and disinhibiting effects of alcohol to reduce anxiety, encourage emotional expression and make social interactions easier to deal with.

The present study also supported a mediating role of alexithymia in the relationship between social anxiety and deficient theory of mind, implying that the latter relationship (Hezel \& McNally, 2013; Washburn et al., 2016) may be partially explained by high levels of alexithymia as reported in SAD samples. Theory of mind reasoning errors would seem likely to lead to negative interpersonal outcomes, thereby promoting and maintaining social anxiety. Likewise, the difficulties identifying and describing one's own feelings in alexithymia are clearly linked to difficulties in correctly identifying the emotions of others, potentially leading to social difficulties (e.g., Demers \& Koven, 2015; Lyvers et al., 2017). Clinician efforts to improve interpersonal functioning in those who suffer from social anxiety may thus benefit from targeting alexithymia in a relevant subset of such clients. Note however that the present study's finding of partial mediation suggests that deficient theory of mind in social anxiety cannot entirely be accounted for by alexithymia. Gender was the strongest predictor of theory of mind performance in this sample.

The present study had several limitations that necessarily temper its conclusions. As noted earlier, the SIAS specifically assesses anxiety experienced in the context of social interactions and cannot be considered diagnostic of SAD. A review of social anxiety measures (Letamendi \& Stein, 2009) cited the absence of items assessing avoidance of social situations - a crucial feature of SAD - as a limitation of the SIAS. Although the SIAS has been reported to reliably distinguish socially anxious from non-socially anxious 
individuals, and to detect differences between clinic patients with social anxiety and those with other forms of anxiety (Peters, 2000), the SIAS by itself was not regarded by its developers as diagnostic of SAD (Mattick \& Clarke, 1989). However, the current study was not intended to target those with SAD, but rather sought to assess subclinical social anxiety as a continuous variable in relation to alexithymia, with the aim of clarifying conceptual understanding of this relationship in the context of the known links between social anxiety and problematic drinking as well as deficient theory of mind.

As the data gathered in the present study were cross-sectional, the observed relationships among variables - including the evidence supporting mediation - cannot be interpreted to elucidate the nature or direction of causation; appropriately designed longitudinal research is required to address such issues. As noted earlier, there is evidence to suggest that social anxiety may, in at least some cases, have a causal relationship to both alexithymia and problematic drinking (Fukunishi et al., 1997; O’Toole et al., 2013). On the other hand, a highly alexithymic child or adolescent is likely to experience persistent interpersonal difficulties due to their poor ability to interpret and appropriately respond to the emotional states of others (Lyvers, McCann et al., 2018; Vanheule et al., 2006), which in turn would seem likely to promote anxiety in social interactions. Such a deficiency in theory of mind has been suggested to precede or at least help maintain social anxiety (Hezel \& McNally, 2014; Washburn et al., 2016). A final limitation of the present study was the reliance on self-report instruments for operationalization of variables. Such instruments are of course very widely used as they can provide quick and low-cost indices of psychological constructs, however their validity is reliant on (among other things) the participant's awareness and knowledge of themselves. This may be particularly problematic in the context of alexithymia, where there are evident difficulties in identifying and describing feelings. On the other hand, Thorberg et al. (2010) found that 
self-report and observer measures of alexithymia yielded similar results, so this issue may not present a major impediment to interpretation.

Despite the present study's limitations, the findings do support and to some extent clarify a potentially important relationship between social anxiety and alexithymia, as they suggest how alexithymic features and related theory of mind deficits are likely to impact those with social anxiety - including problematic drinking as a common outcome. As the study used a nonclinical sample, the results indicate that alexithymic characteristics are prominent not only among those diagnosed with SAD as found in previous work cited earlier, but also in non-diagnosed young adults who report experiencing anxiety in the context of social interactions.

In conclusion, the present study has provided support for alexithymia as a notable feature in social anxiety. Difficulties experienced by such individuals in identifying and describing their emotions have the potential to perpetuate and maintain social anxiety by interfering with social interactions and normal processes of developing emotional and interpersonal insight. Further, as alexithymia may not only promote and maintain social anxiety but can also increase the risk of additional problems such as AUD, assessment of alexithymia in those with social anxiety may offer fruitful directions for clinical treatment. 


\section{References}

Abrams, K., Kushner, M. G., Medina, K. L., \& Voight, A. (2001). The pharmacologic and expectancy effects of alcohol on social anxiety in individuals with social phobia. Drug and Alcohol Dependence, 64, 219-231. doi:10.1016/S0376$8716(01) 00125-9$

Abrams, K., Kushner, M. G., Medina, K. L., \& Voight, A. (2002). Self-administration of alcohol before and after a public speaking challenge by individuals with social phobia. Psychology of Addictive Behaviors, 16, 121-128. doi:10.1037//0893164X.16.2.121

American Psychiatric Association. (2013). Diagnostic and statistical manual of mental disorders: DSM-V(5th ed.). Washington, DC: American Psychiatric Association.

Amin, N., Foa, E. B., \& Coles, M. E. (1998). Negative interpretation bias in social phobia. Behavior Research and Therapy, 36, 945-957. doi:10.1016/S00057967(98)00060-6

Antony, M. M., Bieling, P. J., Cox, B. J., Enns, M. W., \& Swinson, R. P. (1998). Psychometric properties of the 42-item and 21-item versions of the depression anxiety stress scales in clinical groups and a community sample. Psychological Assessment, 10, 176-181. doi:10.1037/1040-3590.10.2.176

Aust, S., Alkan Härtwig, E., Heuser, I., \& Bajbouj, M. (2013). The role of early emotional neglect in alexithymia. Psychological Trauma: Theory, Research, Practice, and Policy, 5, 225-232. doi:10.1037/a0027314

Babor, T. F., Higgins-Biddle, J. C., Saunders, J. B., \& Monteiro, M. G. (2001). Alcohol use disorders identification test: Guidelines for use in primary health care. Geneva: World Health Organization.

Bagby, R. M., Parker, J. D. A., \& Taylor, G. J. (1994). The twenty-item Toronto 
alexithymia scale-I. item selection and cross-validation of the factor structure. Journal of Psychosomatic Research, 38, 23-32. doi:10.1016/00223999(94)90005-1

Bagby, R. M., Taylor, G. J., \& Parker, J. D. A. (1994). The twenty-item Toronto alexithymia scale-II. convergent, discriminant, and concurrent validity. Journal of Psychosomatic Research, 38, 33-40. doi:10.1016/0022-3999(94)90006-X

Baron, R. M., \& Kenny, D. A. (1986). The moderator-mediator variable distinction in social psychological research. Journal of Personality and Social Psychology, 51, 1173-1182. doi:10.1037/0022-3514.51.6.1173

Baron-Cohen, S., Wheelwright, S., Hill, J., Raste, Y., \& Plumb, I. (2001). The "reading the mind in the eyes" test revised version: A study with normal adults, and adults with asperger syndrome or high-functioning autism. Journal of Child Psychology and Psychiatry and Allied Disciplines, 42, 241-251. doi:10.1017/S0021963001006643

Baxter, A. J., Patton, G., Scott, K. M., Degenhardt, L., \& Whiteford, H. A. (2013). Global epidemiology of mental disorders: What are we missing? PloS One, 8, e65514. doi:10.1371/journal.pone.0065514

Berthoz, S., \& Hill, E. L. (2005). The validity of using self-reports to assess emotion regulation abilities in adults with autism spectrum disorder. European Psychiatry, 20, 291-298. doi:10.1016/j.eupsy.2004.06.013.

Bohn, M. J., Babor, T. F., \& Kranzler, H. R. (1995). The alcohol use disorders identification test (AUDIT): Validation of a screening instrument for use in medical settings. Journal of Studies on Alcohol, 56, 423-432.

doi: $10.15288 /$ jsa.1995.56.423

Brown, E. J., Turovsky, J., Heimberg, R. G., Juster, H. R., Brown, T. A., \& Barlow, D. H. (1997). Validation of the social interaction anxiety scale and the social phobia scale 
across the anxiety disorders. Psychological Assessment, 9, 21-27. doi:10.1037/1040-3590.9.1.21

Brown, T. A., Chorpita, B. F., Korotitsch, W., \& Barlow, D. H. (1997). Psychometric properties of the depression anxiety stress scales (DASS) in clinical samples. Behavior Research and Therapy, 35, 79-89. doi:10.1016/S00057967(96)00068-X

Buckner, J. D., Schmidt, N. B., Lang, A. R., Small, J. W., Schlauch, R. C., \& Lewinsohn, P. M. (2008). Specificity of social anxiety disorder as a risk factor for alcohol and cannabis dependence. Journal of Psychiatric Research, 42, 230-239. doi:10.1016/j.jpsychires.2007.01.002

Clark, D., \& Wells, A. (1997). A cognitive perspective in social phobia. Biological Psychiatry, 42, 134. doi:10.1016/s0006-3223(97)87445-8

Conley, T. B. (2001). Construct validity of the MAST and AUDIT with multiple offender drunk drivers. Journal of Substance Abuse Treatment, 20, 287-295. doi: $10.1016 / \mathrm{S} 0740-5472(01) 00159-3$

Cox, B. J., Swinson, R. P., Shulman, I. D., \& Bourdeau, D. (1995). Alexithymia in panic disorder and social phobia. Comprehensive Psychiatry, 36, 195-198. doi:10.1016/0010-440X(95)90081-6

Dalbudak, E., Evren, C., Aldemir, S., Coskun, K. S., Yıldırım, F. G., \& Ugurlu, H. (2013). Alexithymia and personality in relation to social anxiety among university students. Psychiatry Research, 209, 167-172. doi: 10.1016/j.psychres.2012.11.027

DeGucht, V., Fischler, B., \& Heiser, W. (2004). Neuroticism, alexithymia, negative affect, and positive affect as determinants of medically unexplained symptoms. Personality and Individual Differences, 36,1655-1667. doi: 10.1016/j.paid.2003.06.012 
de Timary, P., Luts, A., Hers, D., \& Luminet, O. (2008). Absolute and relative stability of alexithymia in alcoholic inpatients undergoing alcohol withdrawal: Relationship to depression and anxiety. Psychiatry Research, 157, 105-113. doi:

10.1016/j.psychres.2006.12.008.

Devine, H., Stewart, S. H., \& Watt, M. C. (1999). Relations between anxiety sensitivity and dimensions of alexithymia. Journal of Psychosomatic Research, 47, 145-158. doi:10.1016/j.psychres.2006.12.008.

Ertekin, E., Koyuncu, A., Ertekin, B., \& Ozyildirim, I. (2015). Alexithymia in social anxiety disorder: Is there a specific relationship or is it a feature of comorbid major depression? Anatolian Journal of Psychiatry, 16, 130. doi:10.5455/apd.153110

Evren, B., \& Evren, C. (2007). Relationship between alexithymia and social anxiety in female outpatients with dermatological disorder presenting for psychiatric consultation. Journal of Clinical Psychology in Medical Settings, 14, 258-265. doi:10.1007/s10880-007-9072-9

Evren, C., Evren, B., Dalbudak, E., Ozcelik, B., \& Oncu, F. (2009). Childhood abuse and neglect as a risk factor for alexithymia in adult male substance dependent inpatients. Journal of Psychoactive Drugs, 41, 85-92. doi:

$10.1080 / 02791072.2009 .10400677$

Faul, F., Erdfelder, E., Buchner, A., \& Lang, A.G. (2009). Statistical power analyses using G*Power 3.1: Tests for correlation and regression analyses. Behavior Research Methods, 41, 1149-1160. doi: 10.3758/BRM.41.4.1149

Fehm, L., Beesdo, K., Jacobi, F., \& Fiedler, A. (2008). Social anxiety disorder above and below the diagnostic threshold: Prevalence, comorbidity and impairment in the general population. Social Psychiatry and Psychiatric Epidemiology, 43, 257-265. doi: $10.1007 / \mathrm{s} 00127-007-0299-4$ 
Foa, E. B., Gilboa-Schechtman, E., Amir, N., \& Freshman, M. (2000). Memory bias in generalized social phobia: Remembering negative emotional expressions. Journal of Anxiety Disorders, 14, 501. doi: 10.1016/S0887-6185(00)00036-0

Frewen, P. A., Dozois, D. J., Neufeld, R. W., \& Lanius, R. A. (2008). Meta-analysis of alexithymia in posttraumatic stress disorder. Journal of Traumatic Stress, 21, 243246. doi:10.1002/jts.20320.

Freyberger, H. (1977). Supportive psychotherapeutic techniques in primary and secondary alexithymia. Psychotherapy and Psychosomatics, 28, 337-345. doi:10.1159/000287080

Frith, U. \& Frith, C. D. (2003). Development and neurophysiology of mentalizing. Philosophical Transactions of the Royal Society of London. Series B: Biological Sciences, 358, 459-473. doi:10.1098/rstb.2002.1218

Fukunishi, I., Kikuchi, M., Wogan, J., \& Takubo, M. (1997). Secondary alexithymia as a state reaction in panic disorder and social phobia. Comprehensive Psychiatry, 38, 166-170. doi:10.1016/S0010-440X(97)90070-5

Gilles, D. M., Turk, C. L., \& Fresco, D. M. (2006). Social anxiety, alcohol expectancies, and self-efficacy as predictors of heavy drinking in college students. Addictive Behaviors, 31, 388-398. doi:10.1016/j.addbeh.2005.05.020

Grabe, H. J., Rainermann, S., Spitzer, C., Gänsicke, M., \& Freyberger, H. J. (2000). The relationship between dimensions of alexithymia and dissociation. Psychotherapy and Psychosomatics, 69, 128-131. doi:10.1159/000012380

Haviland, M. G., Hendryx, M. S., Shaw, D. G., \& Henry, J. P. (1994). Alexithymia in women and men hospitalized for psychoactive substance dependence. Comprehensive Psychiatry, 35, 124-128. doi:10.1016/0010-440X(94)90056-N Hezel, D. M., \& McNally, R. J. (2014). Theory of mind impairments in social anxiety 
disorder. Behavior Therapy, 45, 530. doi:10.1016/j.beth.2014.02.010

Infrasca, R. (1997). Alexithymia, neurovegetative arousal and neuroticism: An experimental study. Psychotherapy and Psychosomatics, 66, 276-280.

Iverach, L., \& Rapee, R. M. (2014). Social anxiety disorder and stuttering: Current status and future directions. Journal of Fluency Disorders, 40, 69-82. doi:10.1016/j.jfludis.2013.08.003

Jankowiak-Siuda, K., Baron-Cohen, S., Bialaszek, W., Dopierala, A., Kozlowska, A., \& Rymarczyk, K. (2016). Psychometric evaluation of the 'reading the mind in the eyes' test with samples of different ages from a Polish population. Studia Psychologica, 58, 18-31. doi:10.21909/sp.2016.01.704

Kairouz, S., Gliksman, L., Demers, A., \& Adlaf, E. M., (2002). For all these reasons, I do...drink: A multilevel analysis of contextual reasons for drinking among Canadian undergraduates. Journal of Studies on Alcohol, 63, 600. doi: $10.15288 /$ jsa. 2002.63 .600

Karno, M., Granholm, E., \& Lin, A. (2000). Factor structure of the alcohol use disorders identification test (AUDIT) in a mental health clinic sample. Journal of Studies on Alcohol, 61, 751-758. doi:10.15288/jsa.2000.61.751

Kessler, R. C., Berglund, P., Demler, O., Jin, R., Merikangas, K. R., \& Walters, E. E. (2005). Lifetime prevalence and age-of-onset distributions of DSM-IV disorders in the national comorbidity survey replication. Archives of General Psychiatry, 62, 593-602. doi:10.1001/archpsyc.62.6.593

Kuntsche, E., Knibbe, R., Gmel, G., \& Engels, R. (2005). Why do young people drink? A review of drinking motives. Clinical Psychology Review, 25, 841-861. doi:10.1016/j.cpr.2005.06.002

Lane, R. D., Hsu, C., Locke, D. E. C., Ritenbaugh, C., \& Stonnington, C. M. (2015). Role 
of theory of mind in emotional awareness and alexithymia: Implications for conceptualization and measurement. Consciousness and Cognition, 33, 398-405. doi:10.1016/j.concog.2015.02.004

Letamendi, A.M., \& Stein, M.B. (2009). Issues in the assessment of social phobia: A review. Israel Journal of Psychiatry and Related Sciences, 46, 13-24. PMID: 19728569

Li, S., Zhang, B., Guo., Y., \& Zhang, J. (2015). The association between alexithymia as assessed by the 20-item Toronto Alexithymia Scale and depression: A metaanalysis. Journal of Psychiatry Research, 227, 1-9. doi:10.1016/j.psychres.2015.02.006.

Lombardo, M. V., Chakrabarti, B., Bullmore, E. T., \& Baron-Cohen, S. (2011). Specialization of right temporo-parietal junction for mentalizing and its relation to social impairments in autism. Neuroimage, 56, 1832-1838. doi: 10.1016/j.neuroimage.2011.02.067

Lovibond, S. H., \& Lovibond, P. F. (1995). Manual for the depression anxiety stress scales. Sydney: Psychology Foundation.

Lyvers, M., Hanigan, C., \& Thorberg, F.A. (2018). Social interaction anxiety, alexithymia, and drinking motives in Australian university students. Journal of Psychoactive Drugs (early online). doi: 10.1080/02791072.2018.1517228

Lyvers, M., Hasking, P., Albrecht, B., \& Thorberg, F. A. (2012). Alexithymia and alcohol: The roles of punishment sensitivity and drinking motives. Addiction Research \& Theory, 20, 348-357. doi:10.3109/16066359.2011.636494

Lyvers, M., Kohlsdorf, S. M., Edwards, M. S., \& Thorberg, F. A. (2017). Alexithymia and mood: Recognition of emotion in self and others. American Journal of Psychology, 130, 88-92. doi: 10.5406/amerjpsyc.130.1.0083 
Lyvers, M., McCann, K., Coundouris, S., Edwards., M. S., Thorberg, F. A. (2018). The externally oriented thinking facet of alexithymia in relation to alcohol consumption, facial emotion recognition, and emotional empathy. American Journal of Psychology, 131, 41-51. doi: 10.5406/amerjpsyc.131.1.0041

Magee, W. J., Eaton, W. W., Wittchen, H., McGonagle, K. A., \& Kessler, R. C. (1996). Agoraphobia, simple phobia, and social phobia in the national comorbidity survey. Archives of General Psychiatry, 53, 159-168. doi:

10.1001/archpsyc.1996.01830020077009

Mattick, R. P., \& Clarke, J. C. (1998). Development and validation of measures of social phobia scrutiny fear and social interaction anxiety. Behavior Research and Therapy, 36, 455. doi:10.1016/S0005-7967(97)10031-6

Moriguchi, Y., Ohnishi, T., Lane, R. D., Maeda, M., Mori, T., Nemoto, K., . . Komaki, G. (2006). Impaired self-awareness and theory of mind: An fMRI study of mentalizing in alexithymia. Neuroimage, 32, 1472-1482. doi: 10.1016/j.neuroimage.2006.04.186

Morris, E. P., Stewart, S. H., \& Ham, L. S. (2005). The relationship between social anxiety disorder and alcohol use disorders: A critical review. Clinical Psychology Review, 25, 734-760. doi:10.1016/j.cpr.2005.05.004

Nemiah, J. C., Freyberger, H., \& Sifneos, P. E. (1976). Alexithymia: A view of the psychosomatic process. In O. Hill (Ed.), Modern trends in psychosomatic medicine (Vol. 3, pp. 430-439). London: Butterworths.

Olderbak, S., Wilhelm, O., Olaru, G., Geiger, M., Brenneman, M. W., \& Roberts, R. D. (2015). A psychometric analysis of the Reading the Mind in the Eyes Test: Toward a brief form for research and applied settings. Frontiers in Psychology, 6, 1503. doi:10.3389/fpsyg.2015.01503 
Onuoha, R. C., Quintana, D. S., Lyvers, M., \& Guastella, A. J. (2016). A meta-analysis of theory of mind in alcohol use disorders. Alcohol and Alcoholism, 51, 410-415. doi:10.1093/alcalc/agv137

O'Toole, M. S., Hougaard, E., \& Mennin, D. S. (2013). Social anxiety and emotion knowledge: A meta-analysis. Journal of Anxiety Disorders, 27, 98-108. doi:10.1016/j.janxdis.2012.09.005

Peters, L. (2000). Discriminant validity of the Social Phobia and Anxiety Inventory (SPAI), the Social Phobia Scale (SPS) and the Social Interaction Anxiety Scale (SIAS). Behavior Research \& Therapy, 38, 943-950. PMID: 10957828

Pinaquy, S., Chabrol, H., Simon, C., Louvet, J.P., \& Barbe, P. (2003). Emotional eating, alexithymia, and binge-eating disorder in obese women. Obesity, 11, 195-201. doi: 10.1038/oby.2003.31

Qualter, P., Quinton, S.J., Wagner, H., \& Brown, S. (2009). Loneliness, interpersonal distrust, and alexithymia in university students. Journal of Applied Social Psychology, 39, 61461-1479. doi: 1559-1816.2009.00491.x

Roh, D., Kim, W. J., \& Kim, C. H. (2011). Alexithymia in obsessive-compulsive disorder: clinical correlates and symptom dimensions. Journal of Nervous and Mental Disease, 199, 690-695. doi:10.1097/NMD.0B013e18229d209.

Ruscio, A. M., Brown, T. A., Chiu, W. T., Sareen, J., Stein, M. B., \& Kessler, R. C. (2008). Social fears and social phobia in the USA: Results from the national comorbidity survey replication. Psychological Medicine, 38, 15-28. doi:10.1017/S0033291707001699

Sabbagh, M. A. (2004). Understanding orbitofrontal contributions to theory-of-mind reasoning: Implications for autism. Brain and Cognition, 55, 209-219. doi:10.1016/j.bandc.2003.04.002 
Saunders, J. B., Aasland, O. G., Babor, T. F., De La Fuente, J. R., \& Grant, M. (1993). Development of the alcohol use disorders identification test (AUDIT): WHO collaborative project on early detection of persons with harmful alcohol Consumption. Addiction, 88, 791-804. doi:10.1111/j.1360-0443.1993.tb02093.x

Schlenker, B. R., \& Leary, M. R. (1982). Social anxiety and self-presentation: A conceptualization model. Psychological Bulletin, 92, 641-669. doi:10.1037/00332909.92.3.641

Schry, A.R., \& White, S.W. (2013). Understanding the relationship between social anxiety and alcohol use in college students: A meta-analysis. Addictive Behaviors, 38, 2690-706. doi: 10.1016/j.addbeh.2013.06.014. Epub 2013 Jun 28.

Sifneos, P. E. (1973). The prevalence of alexithymic' characteristics in psychosomatic patients. Psychotherapy and Psychosomatics, 22, 255-262.

Sobel, M. E. (1982). Asymptotic intervals for indirect effects in structural equations models. In S. Leinhart (Ed.), Sociological methodology (pp. 290-312). San Francisco: Jossey-Bass.

Speranza, M., Corcos, M., Stéphan, P., Loas, G., Pérez-Diaz, F., Lang, F., . . Jeammet, P. (2004). Alexithymia, depressive experiences, and dependency in addictive disorders. Substance Use \& Misuse, 39, 551-579. doi:10.1081/JA-120030058

Spokas, M., Luterek, J. A., \& Heimberg, R. G. (2009). Social anxiety and emotional suppression: The mediating role of beliefs. Journal of Behavior Therapy and Experimental Psychiatry, 40, 283-291. doi:10.1016/j.jbtep.2008.12.004

Stemberger, R. T., Turner, S. M., Beidel, D. C., \& Calhoun, K. S. (1995). Social phobia: An analysis of possible developmental factors. Journal of Abnormal Psychology, 104, 526-531. doi:10.1037//0021-843X.104.3.526

Summerfeldt, L. J., Kloosterman, P. H., Antony, M. M., McCabe, R. E., \& Parker, J. D. A. 
(2010). Emotional intelligence in social phobia and other anxiety disorders. Journal of Psychopathology and Behavioral Assessment, 33, 69. doi:

$10.1007 / \mathrm{s} 10862-010-9199-0$

Swart, M., Kortekaas, R., \& Aleman, A. (2009). Dealing with feelings: Characterization of trait alexithymia on emotion regulation strategies and cognitive-emotional processing. PlosOne. doi:10.1371/journal.pone.0005751

Taylor, G. J., Bagby, R. M., \& Parker, J. D. A. (1997). Disorders of affect regulation: Alexithymia in medical and psychiatric illness. Cambridge (UK): Cambridge University Press.

Taylor, G. J., Bagby, R. M., \& Parker, J. D. A. (2003). The 20-item Toronto alexithymia scale. IV. reliability and factorial validity in different languages and cultures. Journal of Psychosomatic Research, 55, 277-283. doi:10.1016/S00223999(02)00601-3

Thomas, S. E., Randall, C. L., \& Carrigan, M. H. (2003). Drinking to cope in socially anxious individuals: A controlled study. Alcoholism: Clinical and Experimental Research, 27, 1937-1943. doi:10.1097/01.ALC.0000100942.30743.8C

Thorberg, F. A., Young, R. M., Sullivan, K. A., \& Lyvers, M. (2009). Alexithymia and alcohol use disorders: A critical review. Addictive Behaviors, 34, 237-245.

Thorberg, F. A., Young, R. M., Sullivan, K. A., Lyvers, M., Connor, J. P., \& Feeney, G. F. X. (2010). A psychometric comparison of the Toronto Alexithymia Scale (TAS-20) and the Observer Alexithymia Scale (OAS) in an alcohol-dependent sample. Personality and Individual Diffierences, 49, 119-123. doi:

10.1016/j.paid.2010.03.018

Thorberg, F. A., Young, R. M., Sullivan, K. A., Lyvers, M., Hurst, C. P., Connor, J. P., \& Feeney, G. F. (2011a). Alexithymia in alcohol dependent patients is partially 
mediated by alcohol expectancy. Drug and Alcohol Dependence, 116, 238-241. doi: 10.1016/j.drugalcdep.2010.11.015

Thorberg, F.A., Young, R., Sullivan, K.A., \& Lyvers, M. (2011b). Parental bonding and alexithymia: A meta-analysis. European Psychiatry, 26, 187-193. doi: 10.1016/j.eurpsy.2010.09.010

Thorberg, F. A., Young, R. McD., Sullivan, K. A., Lyvers, M., Hurst, C., Tyssen, R., Noble, E. P., London, E. D., Connor, J. P., \& Feeney, GFX. (2016a). A prospective mediational study on the stability of alexithymia among alcohol-dependent outpatients in Cognitive-Behavioral Therapy. Psychology of Addictive Behaviors, 30, 64-72.

Thorberg, F. A., Young, R. M., Lyvers, M., Sullivan, K. A., Hasking, P., London, E. D., . . Feeney, G. F. X. (2016b). Alexithymia in relation to alcohol expectancies in alcohol-dependent outpatients. Psychiatry Research, 236, 186. doi:10.1016/j.psychres.2016.01.016

Torvik, F.A., Welander-Vatn, A., Ystrom, E., Knudsen, G.P., Czajkowski, N., Kendler, K.S., \& Reichborn-Kjennerud, T. (2016). Longitudinal associations between social anxiety disorder and avoidant personality disorder: A twin study. Journal of Abnormal Psychology, 125, 114-124. doi: 10.1037/abn0000124.

Turk, C., Heimberg, R., Luterek, J., Mennin, D., \& Fresco, D. (2005). Emotion dysregulation in generalized anxiety disorder: A comparison with social anxiety disorder. Cognitive Therapy and Research, 29, 89-106. doi:10.1007/s10608-005$1651-1$

Vallante, M., Baron-Cohen, S., Melis, M., Marrone, M., Petretto, D. R., Masala, C., \& Preti, A. (2013). The "reading the mind in the eyes" test: Systematic review of psychometric properties and a validation study in Italy. Cognitive 
Neuropsychiatry, 18, 326-354. doi:10.1080/13546805.2012.721728

Vanheule, S., Desmet, M., Meganck, R., \& Bogaerts, S. (2006). Alexithymia and interpersonal problems. Journal of Clinical Psychology, 63, 109-117. doi:10.1002/jclp.20324.

Washburn, D., Wilson, G., Roes, M., Rnic, K., \& Harkness, K.L. (2016). Theory of mind in social anxiety disorder, depression, and comorbid conditions. Journal of Anxiety Disorders, 37, 71-7. doi: 10.1016/j.janxdis.2015.11.004.

Wastell, C. A., \& Taylor, A. J. (2002). Alexithymic mentalising: Theory of mind and social adaptation. Social Behavior and Personality, 30, 141-148. doi: $10.2224 /$ sbp.2002.30.2.141

Wells, A. (1997). Cognitive therapy of anxiety disorders: A practice manual and conceptual guide. Chichester, UK: Wiley.

Werner, K., Goldin, P., Ball, T., Heimberg, R., \& Gross, J. (2011). Assessing emotion regulation in social anxiety disorder: The emotion regulation interview. Journal of Psychopathology and Behavioral Assessment, 33, 346-354. doi:10.1007/s10862011-9225-X 
Table 1

Pearson's Product Moment Correlations, Means and Standard Deviations for all variables of interest.

\begin{tabular}{|c|c|c|c|c|c|c|c|c|c|c|c|c|c|}
\hline Scale & 2 & 3 & 4 & 5 & 6 & 7 & 8 & 9 & 10 & 11 & 12 & $M$ & $S D$ \\
\hline 1. SIAS & $.55^{* * *}$ & $.50 * * *$ & $.51 * * *$ & .03 & $-.22 * *$ & $.38 * * *$ & $.17 * *$ & .08 & $.20 * *$ & $.21 * *$ & $.21 * *$ & 28.60 & 11.96 \\
\hline 2. TAS-20 & - & $.76^{* * *}$ & $.88 * * *$ & $.21 * *$ & $-.24 * * *$ & $.52 * * *$ & $.33 * * *$ & $.23 * * *$ & $.34 * * *$ & $.32 * * *$ & $.34 * * *$ & 49.13 & 13.05 \\
\hline 3. TAS DDF & & - & $.66^{* * *}$ & $.25 * * *$ & -.12 & $.39 * * *$ & .12 & .11 & .10 & $.16^{*}$ & $.13 *$ & 14.15 & 3.33 \\
\hline 4. TAS DIF & & & - & $.22 * *$ & $-.15^{*}$ & $.55 * * *$ & $.29 * * *$ & $.16^{*}$ & $.30 * * *$ & $.31 * * *$ & $.31 * * *$ & 16.43 & 6.57 \\
\hline 5. TAS EOT & & & & - & .03 & -.00 & .01 & -.01 & -.03 & .05 & .02 & 25.62 & 3.21 \\
\hline 6. RMET-R & & & & & - & -.10 & $-.20 * *$ & $-.17 *$ & $-.28 * * *$ & $-.19 * *$ & $-.20 * *$ & 24.74 & 6.27 \\
\hline 7. DASS Depression & & & & & & - & $.21 * *$ & .11 & $.24 * * *$ & $.21 * *$ & $.23 * * *$ & 5.55 & 5.22 \\
\hline 8. AUDIT & & & & & & & - & $.74 * * *$ & $.83 * * *$ & $.86^{* * *}$ & $.95 * * *$ & 9.21 & 5.85 \\
\hline 9. AUDIT Consumption & & & & & & & & - & $.47 * * *$ & $.48 * * *$ & $.51 * * *$ & 5.25 & 2.16 \\
\hline 10. AUDIT Dependence & & & & & & & & & - & $.63 * * *$ & $.86 * * *$ & 1.07 & 1.79 \\
\hline 11. AUDIT Problems & & & & & & & & & & - & $.92 * * *$ & 3.00 & 3.20 \\
\hline 12. Problem Drinking & & & & & & & & & & & - & 4.00 & 4.46 \\
\hline
\end{tabular}

Note. ${ }^{*} p<.05 * * p<.01 * * * p<.001$. SIAS $=$ Social Interaction Anxiety Scale TAS-20 = Toronto Alexithymia Scale 20. TAS DDF $=$ Difficulty Describing Feelings Subscale, TAS DIF = Difficulty Identifying Feelings Subscale. TAS EOT = Externally Oriented Thinking Subscale. RMET-R = Reading the Mind in the Eyes Test Revised. DASS Depression = Depression Anxiety Stress Scales Depression Scale. AUDIT $=$ Alcohol Use Disorder Identification Test. AUDIT Consumption $=$ Consumption subscale. AUDIT Dependence $=$ Dependence subscale. AUDIT Related Problems = Alcohol-Related Problems subscale. Problem Drinking = combined Dependence and Alcohol-Related Problems subscales. 
Table 2

Hierarchical regression coefficients for demographic variables, depression and social anxiety predicting alexithymia.

\begin{tabular}{|c|c|c|c|c|c|c|c|}
\hline & Predictors & $\mathrm{R}^{2}$ & $\Delta \mathrm{R}^{2}$ & $\beta$ & $B$ & $\operatorname{SE} B$ & $95 \% \mathrm{CI}$ \\
\hline \multirow[t]{5}{*}{ Step 1} & & $.28 * * *$ & & & & & \\
\hline & Constant & & & & 46.19 & 4.78 & {$[36.78,55.60]$} \\
\hline & Age & & & -.08 & -.24 & .16 & {$[-.56, .08]$} \\
\hline & Gender & & & .03 & .83 & 1.48 & {$[-2.09,3.76]$} \\
\hline & Depression & & & $.51 * * *$ & 1.29 & .14 & {$[1.01,1.56]$} \\
\hline \multirow[t]{6}{*}{ Step 2} & & $.42 * * *$ & $.14 * * *$ & & & & \\
\hline & Constant & & & & 34.07 & 4.55 & {$[25.73,43.67]$} \\
\hline & Age & & & -.04 & -.12 & .15 & {$[-.41, .17]$} \\
\hline & Gender & & & -.02 & -.38 & 1.34 & {$[-3.03,2.27]$} \\
\hline & Depression & & & $.36^{* * *}$ & .89 & .14 & {$[.62,1.16]$} \\
\hline & Social Anxiety & & & $.41 * * *$ & .45 & .06 & {$[.33, .57]$} \\
\hline
\end{tabular}

Note. ${ }^{* * *} p<.001 . \mathrm{SE}=$ Standard Error. $\mathrm{CI}=$ Confidence Intervals. 
Table 3

Hierarchical regression coefficients for age, gender, depression, social anxiety and alexithymia predicting problematic drinking.

\begin{tabular}{|c|c|c|c|c|c|c|c|}
\hline & Predictors & $\mathrm{R}^{2}$ & $\Delta \mathrm{R}^{2}$ & $\beta$ & $B$ & $\mathrm{SE} B$ & $95 \% \mathrm{CI}$ \\
\hline \multirow[t]{5}{*}{ Step 1} & & $.06^{* *}$ & & & & & \\
\hline & Constant & & & & 4.28 & 1.86 & {$[.61,7.94]$} \\
\hline & Age & & & -.02 & -.02 & .06 & {$[-.15, .10]$} \\
\hline & Gender & & & -.06 & -.53 & .58 & {$[-1.67, .61]$} \\
\hline & Depression & & & $.23 * * *$ & .20 & .05 & {$[.09, .30]$} \\
\hline \multirow[t]{6}{*}{ Step 2} & & $.08^{* *}$ & $.02 *$ & & & & \\
\hline & Constant & & & & 2.90 & 1.96 & {$[-.96,6.75]$} \\
\hline & Age & & & -.01 & -.01 & .06 & {$[-.13, .12]$} \\
\hline & Gender & & & -.07 & -.67 & .58 & {$[-1.81, .47]$} \\
\hline & Depression & & & $.17 *$ & .15 & .06 & {$[.03, .26]$} \\
\hline & Social Anxiety & & & $.15^{*}$ & .05 & .03 & {$[.00, .11]$} \\
\hline
\end{tabular}

Step 3 $.13^{* * *} \quad .05^{* * *}$

Constant

Age

Gender

Depression

Social Anxiety

Alexithymia

$$
-.61 \quad 2.13 \quad[-4.80,3.59]
$$$$
.00 \quad .06 \quad[-.12, .13]
$$

$-.07$

$-.64 \quad .56 \quad[-1.75, .47]$

.07

$.06 \quad .06 \quad[-.06, .18]$

.02

$.01 \quad .03$

$[-.05, .06]$

$.30^{* * *}$

$.10 \quad .03$

$[.05, .16]$

Note. ${ }^{*} p<.05 * * p<.01 * * * p<.001 . \mathrm{SE}=$ Standard Error. $\mathrm{CI}=$ Confidence Intervals. 
Table 4

Hierarchical regression coefficients for age, gender, depression, social anxiety and alexithymia predicting theory of mind.

\begin{tabular}{|c|c|c|c|c|c|c|c|}
\hline & Predictors & $\mathrm{R}^{2}$ & $\Delta \mathrm{R}^{2}$ & $\beta$ & $B$ & SE $B$ & $95 \% \mathrm{CI}$ \\
\hline \multirow[t]{5}{*}{ Step 1} & & $.05^{*}$ & & & & & \\
\hline & Constant & & & & 20.49 & 2.63 & {$[15.31,25.67]$} \\
\hline & Age & & & .03 & .04 & .09 & {$[-.13, .22]$} \\
\hline & Gender & & & $.19 * *$ & 2.41 & .82 & {$[.80,4.02]$} \\
\hline & Depression & & & -.09 & -.11 & .08 & {$[-.26, .04]$} \\
\hline \multirow[t]{6}{*}{ Step 2} & & $.09 * * *$ & $.05^{* *}$ & & & & \\
\hline & Constant & & & & 23.68 & 2.72 & {$[18.31,29.05]$} \\
\hline & Age & & & .01 & .01 & .09 & {$[-.16, .18]$} \\
\hline & Gender & & & $.21^{* *}$ & 2.75 & .80 & {$[1.16,4.33]$} \\
\hline & Depression & & & -.00 & -.00 & .08 & {$[-.16, .16]$} \\
\hline & Social Anxiety & & & $-.24 * *$ & -.13 & .04 & {$[-.20,-.06]$} \\
\hline
\end{tabular}

Step 3

$.11^{* * *} \quad .02 *$

Constant

Age

Gender

Depression

Social Anxiety

Alexithymia
$26.78 \quad 3.01$

$[20.85,32.72]$

$-.00$

$\begin{array}{ll}-.00 & .09\end{array}$

$[-.17, .17]$

$.21^{* *}$

$2.71 \quad .80$

$[1.14,4.28]$

.07

$.08 \quad .09$

$[-.09, .25]$

$\begin{array}{llll}-.16^{*} & -.09 & .04 & {[-.16,-.01]}\end{array}$

$\begin{array}{lll}-.19 * & -.09 & .04\end{array}$

$[-.17,-.01]$

Note. ${ }^{*} p<.05 * * p<.01 * * * p<.001 . \mathrm{SE}=$ Standard Error. $\mathrm{CI}=$ Confidence Intervals. 